\title{
O estatuto do inconsciente é ético
}

Bruno de Almeida Guimarães

Professor da Faculdade de Filosofia do Instituto Santo Inácio (Centro de Estudos Superiores da Companhia de Jesus) 


\section{O estatuto do inconsciente é ético}

O objetivo deste trabalho é discutir esta afirmação de Lacan para mostrar não só que a "realidade" do inconsciente é problemática e, portanto, deve ser abordada a partir de um estatuto ético, mas que a própria prática psicanalítica também pode ser pensada a partir desse estatuto. Ou seja, que podemos pensar a psicanálise como uma ética do real, uma ética do encontro traumático, do encontro com o impasse, ou do encontro com o inassimilável.

Palavras-chave: psicanálise, ética, real, paradoxos do gozo, impasses, "saber fazer com"

\section{The ethical status of the unconscious}

The aim of the paper is to discuss Lacan's phrase in the title so as to show not only that the reality of the unconscious is problematic and requires an ethical approach but also that such an approach is recommended to psychoanalytical practice in general. Psychoanalysis would then be conceived as an ethics of the real - of the encounter with the traumatic, the critical or the unassimilable.

Key words: psychoanalysis, ethics, real, rejoice, crisis

Em seu seminário de 1959-60, dedicado à ética da psicanálise, Lacan se propõe a extrair "as conseqüências éticas gerais que a relação com o inconsciente, tal como foi aberto por Freud, comporta" (Lacan, 12, p.350). Os parâmetros para progredir nesse domínio se articulariam, segundo Lacan, "por meio de uma orientação do referenciamento do homem em relação ao real”. Para conceber isso, seria preciso "ver o que ocorreu no intervalo entre Aristóteles e Freud" (Lacan, 12, p.21).

Antes, porém, talvez fosse oportuno extrair desses dois pontos extremos uma comparação. Ao definir o princípio de realidade freudiano como aparelho de retificação responsável por uma atividade de retorno e retenção, Lacan se pergunta se a aposta num princípio retificador não seria próximo daquilo que se lê na Ética a Nicômaco (Lacan,12, p. 41). Afinal, de modo semelhante ao que Freud articula sobre o princípio de realidade, não é difícil reconhecer, em Aristóteles, a sugestão de que um prazer postergado, que causa uma dor momentânea, pode permitir o acesso a um bem maior e mais duradouro. Para Aristóteles, a questão seria, propriamente, saber reconhecer o verdadeiro bem e orientar-se em direção a ele. O problema é justamente que, em Freud, esse princípio retificador, o princípio de realidade, falha diante de algo que não é acessível aos processos do pensamento.

Contudo, voltando ao que teria ocorrido no intervalo entre Aristóteles e Freud, Lacan destaca o declínio da "função do mestre" e a conversão, ou reversão utilitarista, no início do século XIX. Ela pressupõe não só o corte da revolução científica, com sua recusa 
da imutabilidade das "idéias eternas", mas também a rejeição, por princípio, da figura do antigo sábio supostamente capaz de conhecer o bem - ou, ao menos, da rejeição do conhecimento de um bem que não seja prosaico e referido a um cálculo estritamente instrumental.

$O$ verdadeiro desafio seria seguir, com Freud, toda uma exploração da ética, incidindo não sobre o domínio do ideal, mas, ao contrário, sobre um aprofundamento da noção de real (Lacan,12, p.21). Nesse ponto, segundo Lacan, encontraríamos um traço bastante distintivo do projeto de Freud também em relação aos idealistas da tradição filosófica, pois, se os idealistas não contestam exatamente a chamada realidade, acabam por domá-la, já que encontram em nós mesmos uma medida para ela. A posição de Freud, por outro lado, não seria tão reconfortante, pois, ao perceber como é precário o acesso à "realidade", compreendeu por que seus mandamentos são tão tirânicos (Lacan, 12, p. 43).

Será que podemos supor que Lacan pretende extrair disso a conclusão de que a ética da psicanálise deveria se fundar numa tirania da "realidade"? Afinal, Lacan estaria convencido de que essa tirania era suficiente para justificar um ataque à ética do idealismo alemão, desprezando as considerações conseqüentes sobre a fragilidade de uma ética fundada num fato empírico existente?

Penso não ser esse o caso. Ao contrário, além de encontrarmos no seminário da ética a sugestão de que é exatamente a ausência de ontologia na obra de Freud que exige a construção de uma ética freudiana, Lacan afirmaria, no seu Seminário XI, que "o estatuto do inconsciente é ético, e não ôntico” (Lacan, 13, p. 37).

Mas de que real estaria Lacan falando, então?

É nesse ponto, e não na defesa do bem empírico capaz de servir ao maior número de pessoas, que a referência ao utilitarismo faz sentido para a psicanálise. Com Jeremy Bentham, aprenderíamos a situar o real, por oposição ao fictitious, no centro da discussão ética.

Bentham teria chegado à noção de ficção analisando uma série de entidades necessárias ao discurso jurídico que não possuíam nenhu- ma realidade substancial. Noções como "contrato social" e "pessoa jurídica”, que têm um estatuto ontológico problemático, são ficções pressupostas sem as quais o Direito não funciona. Disso, concluiria que, apesar de serem criadas e nomeadas pelo espírito humano, as entidades ficcionais são capazes de produzir uma série de efeitos na realidade.

Assim, Bentham nos ajuda a perceber que a realidade é simbolicamente constituída. Sem o discurso ela perde consistência ${ }^{1}$. Tal conclusão levaria Lacan a situar toda a experiência freudiana num movimento de báscula entre ficção e real.

O real, nesse contexto, seria aquilo que é impossível de simbolizar, ou o que não se submete à "virtualização". Ele coincidiria com o ponto irredutível à tradução completa do inconsciente para torná-lo consciente de que falava Freud em 1920, ao introduzir o conceito de pulsão de morte como algo "além do princípio do prazer"2. Por outro lado, "em Freud, a característica do prazer, como dimensão do que encadeia o homem, encontra-se totalmente no lado do fictício. O fictício efetivamente não é, por essência, o que é enganador, mas, propriamente falando, o que chamamos de simbólico" (Lacan, 12, p. 22).

Freud teria apresentado a noção de pulsão de morte para caracterizar a ação no aparelho psíquico de um mecanismo que funciona para além do princípio do prazer, mas Lacan lembra que a lei moral se afirma igualmente contra o prazer. Isso nos leva à tese fundamental do seminário da ética, que é demonstrar "que a lei moral, o man-

\footnotetext{
Lacan lembra que, em Bentham, o fictitious está longe de ser o ilusório ou enganador. O termo não poderia ser propriamente traduzido por fictício, a menos que entendêssemos que "toda verdade tem uma estrutura de ficção" (Lacan 12 , p. 22).

${ }^{2}$ Freud relata como, após vinte e cinco anos de prática, ele haveria de se deparar com esse limite que não pode ser reintegrado ao campo do sentido. Segundo ele, "o objetivo que [antes] fora estabelecido - o de que o inconsciente deve tornar-se consciente - não era completamente atingível", pois "o paciente não pode recordar a totalidade do que nele se acha reprimido, e o que não lhe é possível recordar pode ser exatamente a parte essencial" (Freud 4, p. 31).
} 
damento moral, ou mesmo a presença da instância moral, é aquilo por meio do qual o real se apresenta na prática analítica estruturada pelo simbólico" (Lacan, 12, p. 31).

A demonstração dessa tese supõe que a situemos no contexto dos paradoxos do gozo sacrificial da consciência moral que aparecem na reformulação teórica de Freud posterior ao Além do princípio do prazer.

Em "mal-estar da civilização", Freud se pergunta de que modo a civilização consegue barrar a pulsão desagregadora e agressiva. A resposta poderia estar na instalação do sentimento de culpa. A civilização exige renúncias, fazendo com que a agressividade seja recalcada. Sendo assim, a pulsão agressiva seria internalizada e "volta para o lugar de onde veio" (Freud, 5, p. 146). Uma parte do ego se encarregaria dessa agressividade. Daí a origem do superego, que, desse momento em diante, irá dirigir toda a agressividade recalcada contra o próprio ego na forma de sentimento de culpa ou necessidade de punição.

Partindo do pressuposto de que não há, para nosso aparelho psíquico, uma distinção entre satisfazer um desejo proibido e desejar, Freud propõe que, ao menor sinal de desejo, o processo repressivo é acionado. Um círculo vicioso faz com que as tentações sejam aumentadas pelas frustrações constantes. Quanto mais frustradas são nossas tentativas de realizar desejos, mais tentados ficamos e mais punição vamos sofrer por parte do superego. Portanto, "quanto mais virtuoso um homem é, mais severo e desconfiado é o seu comportamento, de maneira que, em última análise, são precisamente as pessoas que levam mais longe a santidade as que se censuram da pior pecaminosidade" (Freud, 5, p. 149)
Lacan esclarece na Ética que Freud escreve O mal-estar na civilização para nos dizer que tudo o que passa do gozo à interdição vai no sentido de um reforço sempre crescente da mesma. “Todo aquele que se aplica em submeter-se à lei moral sempre vê reforçarem-se as exigências, sempre mais minuciosas e mais cruéis de seu supereu" (Lacan, 12, p. 216). Contudo, para insinuar também que a interdição alimenta o próprio gozo, Lacan se pergunta se não poderíamos dizer que ocorre o mesmo no sentido contrário:

Não é absolutamente o caso que aquele que avança na via do gozo sem freios, em nome de qualquer forma que seja de rejeição moral, encontra obstáculos cuja vivacidade sob inúmeras formas nossa experiência nos mostra todos os dias, e que, talvez, não deixam de supor algo único na raiz? É nesse ponto que chegamos à fórmula de que uma transgressão é necessária para aceder a esse gozo, e que - para reencontrarmos São Paulo ${ }^{3}$ - é muito precisamente para isso que serve a Lei. A transgressão no sentido do gozo só se efetiva apoiando-se no princípio contrário, sob as formas da Lei. (Lacan, 12, pp. 216 - 217)

Aqui encontramos, em Lacan, uma inversão dialética digna de Hegel, pois até mesmo a revolta e a transgressão deixam de ser pensadas como exteriores à ordem para se mostrarem diretamente solicitadas por ela como o Outro necessário a sua própria sustentação. A inversão lacaniana aparece aí para mostrar que, se desde Freud o superego é um imperativo que exige um sacrifício sempre maior, se ele é um imperativo que exige o gozo da dor, a Lei não barra o gozo, ela o produz. Daí o famoso jogo homofônico em "subversão do sujeito": "viesse a Lei a ordenar 'Goza' (jouis) o sujeito só poderia responder a isso com um 'Ouço' (j’oüs), onde o gozo não seria mais do que subentendido” (Lacan, 7, p. 836).

${ }^{3}$ A referência a São Paulo é esclarecida numa frase logo abaixo, em que Lacan complementa: "Foi preciso que o pecado tivesse tido a Lei para que ele, diz São Paulo, se tivesse tornado - nada diz que ele consegue, mas pôde entrever tornar-se - desmesuradamente pecador" (Lacan. 12, p. 217). 
Assim, percebemos que a exigência do devo pode extrair sua energia da própria exigência da pulsão agressiva, revelando um dever anterior à ordem do superego. $\mathrm{O}$ masoquismo moral deixa de ser incompreensível para se tornar apenas a manifestação de uma pulsão que encontra satisfação através do sintoma. O gozo a que se renuncia só serve para alimentar ainda mais o superego; a renúncia ao gozo nutre o gozo da renúncia do superego. Eis o paradoxo: o imperativo de gozar se mostra absolutista. Com o superego goza-se de um jeito ou de outro. Se não há renúncia, o sujeito goza; se há, o sujeito goza de renunciar.

Portanto, a tese de Lacan segundo a qual a lei moral, ou a presença da instância moral, é aquilo por meio do qual o real se apresenta na prática analítica significa que um dos destinos do real da exigência imperiosa de nossas pulsões se expressa através da atuação do superego. Resta saber se haveriam outros destinos possíveis, ou seja, se existiriam outras formas de gozo capazes de nos apresentar o real. Penso ser essa a questão-chave para se entender a continuidade das futuras elaborações teóricas de Lacan com o Seminário VII.

Sabemos que Lacan procura caminhos alternativos no próprio $\mathrm{Se}$ minário VII, mas não acreditamos que ele tenha encontrado soluções efetivas naquele momento. Voltaremos a isso, mais adiante, para mostrar que a solução trágica apresentada ali pode ser entendida como um impasse na sua teorização. De qualquer modo, o que esse impasse da formulação trágica parece ter ensinado ao próprio Lacan é que o grande desafio ético da psicanálise é saber se o gozo masoquista do imperativo moral pode ser substituído por algum outro gozo, sem que isso implique numa reviravolta para o outro extremo da perversão ${ }^{4}$.

\footnotetext{
${ }^{4}$ E curioso observar que Lacan já havia assinalado alguns problemas no próprio Seminário da ética que mais tarde o levariam à retificação de sua posição. A princípio, ele observa não ter conseguido, após todo seu progresso teórico, levar a psicanálise a algum novo tipo de perversão. (Cf. Lacan, 12, p. 25). Mais adiante, sugere uma proximidade entre a formulação ética de Kant e a de Sade, ao constatar que é na pureza da moral kantiana, isto é, na eliminação de todo aspecto patológico e sentimental que o mundo sadista é concebível. (Cf. Lacan, 12, p. 101). Contudo, ao comentar "dimensão trágica da experiência psicanalítica" e o desejo a ser encontrado no término da análise, que prepara a
}

No "Compte Rendu" escrito ao final de Seminário da ética, Lacan diz que:

[Freud] partiu, ou tornou a partir, do antigo passo da filosofia: ou seja, que a ética não pode derivar da obrigação pura. O homem tende, em seus atos, para um bem. A análise volta a privilegiar o desejo como princípio da ética. Até a censura, a princípio, a única a figurar aí como moral, extrai dele toda sua energia. Não existe outra raiz da ética. (Lacan, 8, p. 8).

Vale aqui a sugestão de Rajchman, em Eros e verdade, de que, na terceira revolução ética operada por Freud, diferentemente do que foi submeter o dever à finalidade da virtude (Aristóteles), ou fazer girar o bem em torno do princípio supremo da obrigação (Kant), teríamos a tarefa de descobrir qual é a melhor maneira de levar a vida (daí a idéia prosaica de tender ao bem), unindo a questão ética do "que fazer?" ao pathos, sem, contudo, retornar a um suposto conhecimento do Bem aristotélico. (Rajchman, 17, p. 41).

Há um dever que nasce da exigência de responder ao encontro traumático com nossas pulsões. É interessante observar que Lacan fala do encontro traumático, no Seminário XI, como a repetição de um encontro com o que é da ordem do acaso (tiquê (Lacan, 13, p. 567). Acho que isso está em sintonia com a fala (de ontem) de Monique David-Ménard sobre a "repetição inventiva" como uma repetição sem um evento primeiro, e é curioso que esteja também em sintonia

torna analista, é no "desejo puro" que Lacan reconhece a exemplaridade da personagem Antígona. (Cf. Lacan, 12, p. 342). Finalmente, no Seminário XI, Lacan retifica sua posição ao afirmar que "a Lei moral, examinada de perto, não é outra coisa senão o desejo em estado puro" e que "o desejo do analista não é um desejo puro" (Cf. Lacan, 13, p. 260). 
com o Ética de Badiou, principalmente quando estabelece algumas aproximações de sua teorização com a ética do desejo de Lacan, esclarecendo que, "ao falar de desejo, Lacan fala aí do não-sabido subjetivo" (Badiou, 2, p. 67). O não "ceder de seu desejo" poderia ser entendido como a ética de um "não ceder naquilo que não se sabe de si” (ibidem, 2, p. 59).

No que diz respeito à passagem do Seminário XI em que Lacan afirma que "o estatuto do inconsciente é ético", a questão pode ser referida ao wo Es war, soll Ich werden e à necessidade de um "saber fazer com" o sintoma, para que Freud pudesse dar uma resposta ao encontro inesperado que teve com a histeria. Lacan afirma que

o estatuto do inconsciente, que eu lhes indico tão frágil no plano ôntico, é ético. Freud, em sua sede de verdade, diz - O que quer que seja, é preciso chegar lá-porque, em alguma parte, esse inconsciente se mostra. E isto ele diz dentro de sua experiência daquilo que era para o médico, até então, a realidade mais recusada, mais coberta, mais contida, mais rejeitada, a da histeria, no que ela é - de algum modo, de origem - marcada pelo signo do engano. (Lacan, 13, p. 37)

Assim, responder a esse encontro inesperado representou um saber fazer com isso que era tão problemático, com a realidade mais recusada até então pelos contemporâneos de Freud.

Em “O engano (La meprise) do sujeito suposto saber”, Lacan reafirma esse caráter frágil ao observar que a questão do inconsciente é a mais mal apreendida até hoje. Ele observa que supor no inconsciente uma mensagem cifrada é diferente de crer na possibilidade de reduzir o escrito enigmático a um único sentido. Mas como ter acesso ao saber inconsciente, então? A resposta de Lacan, nesse caso, seria: "é por tratar-se de um lugar que difere de toda apreensão [prise] do sujeito que um saber é liberado, já que ele só se entrega por meio do que, para o sujeito, é mal apreendido [méprise]" (Lacan, 9, p. 337). Isso é fundamental, pois Lacan descobre que o inconsciente é um saber que só se libera a partir do “engano”. Temos aí algo que só se dá a conhecer de viés, que só se revela efetivamente no momento em que deixamos de ter a pretensão de dominá-lo.

Já no Seminário XXIV, Lacan observa que, apesar de entender que a psicanálise revele um tipo de saber, este não se confundiria com a apreensão conceitual do inconsciente, como a filosofia faria com seus objetos. O saber alcançável numa psicanálise seria apenas o savoir y faire, o "saber fazer com", que é diferente de saber o que fazer. Isso significa saber "se virar" (se débrouiller), mas esse "fazer com" indica que não se apreende realmente a coisa, em suma, em conceito" 5 .

O título desse seminário L’insu que sait de l'une-bévue s'aile à mourre, que nos apresenta uma tradução indecidível ao situar o inconsciente (l'Unbewusstsein, em alemão) nesse "um engano" - l'une-bévue - que levanta vôo ou se sustenta de um jogo de azar, mas que ecoa também a proximidade homofônica do sustentar-se do amor ou até mesmo da morte, já nos dá uma pista de qual é o novo paradigma lacaniano da ética do "savoir y faire" e da ética do bem-dizer. Joyce é o exemplo de um "desabonar o inconsciente", de um saber fazer com a dimensão impositiva da ordem simbólica que coincidiria com esse saber fazer do sinthome.

Joyce "sait y faire - C'est le sinthome" (Lacan, 15, 16/03/1976), diz Lacan no Seminário XXIII, ou seja, ele sabia fazer com isso. Joyce é o sint-homem que sabia fazer cair seu "mandaquinismo" (Lacan, 15, 18/11/1975), seu são-thomas-d'aquinismo ${ }^{6}$ e, portanto, é um herói-ético, herético (heréthique com $\mathrm{h}$ ), um pobre heréthique que sabia que a única arma contra o sintoma é o equívoco (Lacan, 15,

\footnotetext{
"Savoir y faire, c'est autre chose que de savoir faire. Ca veut dire se débrouiller. Mais cet 'y faire' indique qu'on ne prend pas vraiment la chose, en somme, en concept." Para as citações dos seminários inéditos de Lacan, como neste caso, passaremos a indicar a data da lição em que foi feita a afirmação, da seguinte maneira: Lacan, 16, 11/01/1977.

${ }^{6} \mathrm{Cf}$. ainda a seguinte passagem de Joyce, o sinthomem I: "Só há santo a se renunciar à santidade" (Lacan, 11, p. 563)
} 
18/11/1975). Lemos ainda que ele "soube usar seu sinthomem até atingir seu real” (Lacan, 15, 18/11/1975), o mesmo real que Lacan, em Televisão, anuncia ser o "que permite desatar efetivamente aquilo em que consiste o sintoma, ou seja, um nó de significantes" (Lacan, 10, p. 515).

A descoberta de que o inconsciente talvez não se preste à interpretação é contemporânea da descoberta de que o sintoma, apesar de produzir um gozo que não traz benefícios ao sujeito, também não pode ser inteiramente desfeito. No Seminário XX, Lacan demonstra que o gozo que nos acomete de um jeito ou de outro - "esse gozo próprio do sintoma. Gozo opaco, por excluir o sentido" (Lacan, 11, p. 566) - torna inteligível o sintoma como a expressão de um querer diferente do cálculo utilitário. O sintoma produz um gozo que "não serve para nada”, diz Lacan (Lacan, 14, p. 11).

Vocês vêem a relação de tudo isto com a utilidade. É utilitário. Isso torna vocês capazes de servir para alguma coisa, e isto por falta de saber gozar de outro modo que não o de ser gozado, ou jogado, [homofonia do être jouis/être jouet] pois é justamente o gozo que não deveria, que não seria preciso (Lacan, 14, p. 84).

Nessa formulação, o sintoma apresenta algo de paradoxal. Já não é apenas um "estofo", ou um "nó de significantes", capaz de proporcionar a satisfação secundária de uma identificação narcísica ao atribuir ao sujeito uma significação dentro de sua estrutura sócio-simbólica, como era no Lacan até o final dos anos 1950. No momento em que se opõem ao útil e já não servem para nada, os significantes que representam o sujeito deixam de se prestar ao sentido. O sujeito mostra-se não inteiramente assujeitado ao Outro e à significação, embora seu gozo continue a se sustentar de um determinado uso da linguagem.

Portanto, ao seguirmos a elaboração lacaniana posterior ao Seminário da ética, constatamos que o próprio Lacan reproduz, em relação a sua teorização, a virada necessária ao saber fazer com o impasse.
Partiu-se de uma constatação: o real nos é inacessível, há um gozo aí, mas não é possível apropriar-se dele com o sentido. Diante disso, Lacan se pergunta se existem outras vias de acesso ao real. Inicialmente, pensou que talvez um forçamento, uma beleza transgressora como a de Antígona pudesse, no limite, apontar para ele. Então, Lacan descobre que o gozo não precisa se prestar necessariamente ao sentido: ele poderia funcionar também como uma espécie de resistência. Ali o sujeito encontraria satisfação sem estar inteiramente assujeitado ao Outro. Toca-se o real indiretamente. No novo paradigma literário já não temos a beleza trágica de Antígona, mas o savoir y faire de Joyce com a língua. Seu gozo, apesar de não produzir transgressões é igualmente impermeável ao sentido, já que o operar com a ordem simbólica continua a ser a via de acesso a uma satisfação pulsional. Lacan descobre ser possível fazer algum uso da dimensão impositiva de ordem simbólica sobre nós para extrairmos uma satisfação sem a finalidade de produzir sentido.

Não estaria aí a resposta para a ética lacaniana? Se Lacan se queixa no Seminário VII de não ter conseguido, após todo seu progresso teórico, levar a psicanálise a algum novo tipo de perversão (Lacan, 12, p. 25), a nova perspectiva que se abre ao final de seu ensino o levaria a abandonar definitivamente a solução transgressiva. Para entender essa ética não transgressiva basta aproximar, tal como o próprio Lacan muitas vezes o fez, a dimensão impositiva da palavra à ação da lei sobre nós. A verdadeira solução estaria não no mecanismo perverso da desconsideração da lei, mas, antes, na capacidade de reconhecê-la em seu aspecto essencial e fazer um outro uso dela. Isto é, utilizá-la para produzir arranjos que não visem a produção do sentido. O único problema de se tomar essa elaboração final como uma ética é que esse "savoir y faire" não é um saber o que fazer, no sentido de um saber conceitual capaz de orientar o caminho em direção ao bem e nem um "conhecimento" das regras do dever. 
Afinal, se a psicanálise pode ser entendida como uma ética, será que somos capazes de adquirir um logos sobre nossas vidas? Se pensarmos no que ocorreu com o próprio desenvolvimento da teorização psicanalítica no confronto com seus impasses, talvez seja possível reconhecer aí uma lógica minimalista do tipo "um saber fazer com o impasse". Pensamos, por exemplo, num tipo de "lógica" de que o "erro é a solução invertida", que está por trás da atitude em Freud de substituir a teoria da sedução pela teoria da fantasia; a mesma coisa seria verdade a propósito da descoberta de Lacan de que um pequeno deslocamento de perspectiva é suficiente para reconhecer que "o obstáculo já é a solução", a propósito do real do gozo. De qualquer modo, essa lógica só poderia ser reconhecida a posteriori (aprés coup), pois, a priori, não saberíamos como exercê-la, já que nada podemos adiantar antes do confronto com o impasse, isto é, do encontro com o real.

\section{Referências bibliográficas}

1. ARISTÓTELES. Éthique à Nicomaque. Paris: Vrin, 1959.

2. BADIOU, Alain. Ética: um ensaio sobre a consciência do mal. Rio de Janeiro: Relume-Dumará, 1995.

3. BENTHAM, Jeremy. Théorie des Fictions. Paris: Éditions de l'Association Freudienne Internationale, 1996

4. FREUD, Sigmund. “Além do princípio do prazer”. In Edição Standard Brasileira das Obras Psicológicas Completas de Sigmund Freud, vol. XVIII, Rio de Janeiro: Imago Editora, 1987.

5. —_ . "O mal-estar na civilização". In Edição Standard Brasileira das Obra Psicológicas Completas de Sigmund Freud, vol. XXI, Rio de Janeiro: Imago Editora, 1987.

6. KANT, Immanuel. Crítica da razão prática. São Paulo: Martins Fontes, 2002.
7. LACAN, Jacques. "Subversão do sujeito e dialética do desejo no inconsciente freudiano [1960]”. In Escritos. Rio de Janeiro: Jorge Zahar Ed., 1998.

8. — . "Compte rendu avec interpolations du Séminaire de l'Ethique". [1960 [1968] In Ornicar? - Revue du Champ freudien. vol. 28, Janvier 1984.

9. —_. "O engano do sujeito suposto saber [1967]". In Outros Escritos. Rio de Janeiro: Jorge Zahar, 2003.

10. — . "Televisão [1974]". In Outros escritos. Rio de Janeiro: Jorge Zahar, 2003.

11.__ “Joyce, o sinthomem I [1975]". In Outros escritos. Rio de Janeiro: Jorge Zahar, 2003.

12.——. O seminário, livro VII. A ética da psicanálise [1959-60]. Rio de Janeiro: Jorge Zahar, 1991

13.—. O seminário, livro XI. Os quatro conceitos fundamentais da psicanálise [1964]. Rio de Janeiro: Jorge Zahar, 1988.

14.—. O seminário, livro XX. Mais, ainda [1972-73]. Rio de Janeiro: Jorge Zahar, 1985.

15.— Le séminaire, livre XXIII. Le sinthome [1975-76]. Paris: Éd. Hors Commerce de l'Association Freudienne Internationale, 2001.

16. L Le séminaire, livre XXIV. L'insu que sait de l'une-bévue s'aile à mourre [1976-77]. Paris: Éd. Hors Commerce de l'Association Freudienne Internationale, 1998

17.RAJCHMAN, John. Eros e verdade: Lacan, Foucault e a questão da ética. Rio de Janeiro: Jorge Zahar, 1993. 